\title{
Recommendations to Improve Health Outcomes Through Recognizing and Supporting Caregivers
}

\author{
Luci K. Leykum, MD, MBA, MSc 1,2,3,8, Lauren S. Penney, PhD 1,2,5, Stuti Dang, MD, \\ MPH ${ }^{1,6,7}$, Ranak B. Trivedi, PhD 1,8,9,4, Polly H. Noël, PhD 1,2,5, Jacqueline A. Pugh, MD, \\ $M P H^{1,2,5}$, Megan E. Shepherd-Banigan, PhD 1,10,11, Mary Jo Pugh, PhD 1,12,13, \\ Rand Rupper, $M D^{1,12,13}$, Erin Finley, PhD ${ }^{1,2,5}$, Julie Parish-Johnson, MS, LCDC, CRC 1,2,5, \\ Roxana Delgado, PhD ${ }^{1,2,5}$, Kimberly Peacock, EdD ${ }^{1,2,5}$, Andrea Kalvesmaki, PhD ${ }^{1,12,13}$, and \\ Courtney H. Van Houtven, $P h D^{1,10,11}$
}

\begin{abstract}
${ }^{1}$ Department of Veterans Affairs Elizabeth Dole Center of Excellence for Veteran and Caregiver Research, San Antonio, USA; ${ }^{2}$ South Texas Veterans Health Care System, 7400 Merton Minter Blvd, San Antonio, TX 78229, USA; ${ }^{3}$ University of Texas at Austin Dell Medical School, Austin, USA; ${ }^{4}$ VA Greater Los Angeles Health Care System, Los Angeles, USA; ${ }^{5}$ Long School of Medicine, University of Texas Health Science Center at San Antonio, San Antonio, USA; ${ }^{6}$ Miami VA Healthcare System,Miami,USA; ${ }^{7}$ University of Miami School of Medicine,Miami,USA; ${ }^{8}$ VA Palo Alto Health Care System, Palo Alto, USA; ${ }^{9}$ Stanford University School of Medicine,Stanford,USA; ${ }^{10}$ Duke University School of Medicine,Durham, USA ${ }_{i}^{11}$ Center of Innovation To Accelerate Discovery and Practice Transformation, Durham VAMC,Durham,USA; ${ }^{12}$ VA Salt Lake City Health Care System/GRECC,Salt Lake City, USA; ${ }^{13}$ University of Utah Health Care School of Medicine, Salt Lake City, USA
\end{abstract}

J Gen Intern Med 37(5):1265-9

DOI: $10.1007 / \mathrm{s} 11606-021-07247-\mathrm{w}$

This is a U.S. government work and not under copyright protection in the U.S.; foreign copyright protection may apply 2021

The need to integrate health care with "social care," or an understanding of an individual's social context, is wellrecognized by clinicians (https://www.nap.edu/resource/ 25467/09252019Social_Care_recommendations.pdf). With a greater understanding of the impact of social/societal determinants of health $(\mathrm{SDOH})$ on health outcomes, there is increasing focus on assessing peoples' access to resources to meet their daily health needs. SDOH have been defined as "conditions in the social, physical, and economic environment in which people are born, live, work and age (https:// www.healthypeople.gov/2010/hp2020/advisory/SocietalDe terminantsHealth.htm)." These conditions include housing, work conditions, food access, and financial resources. The National Academies of Science, Engineering, and Medicine; World Health Organization; and United States Department of Health and Human Services all recommend assessing individuals' social situations, identifying needs, and meeting those needs through providing appropriate healthcare and community resources (https://www.nap.edu/resource/25467/ 09252019Social_Care_recommendations.pdf, https://www. healthypeople.gov/2010/hp2020/advisory/SocietalDetermi nantsHealth.htm, https://www.who.int/health-topics/socialdeterminants-of-health\#tab=tab_1). Effectively meeting needs requires not only identifying relevant resources, but also expanding the healthcare workforce to better address needs, and developing linkages between health systems and community organizations that provide social support.

Received June 13, 2021

Accepted October 19, 2021

Published online January 3, 2022
Many examples of interventions to address SDOH have been reported (https://health.gov/healthypeople, https://www.cdc. gov/socialdeterminants/cdcprograms/index.htm). ${ }^{1}$ These interventions have largely focused on targeted areas: housing, employment, education, food security, social/community context, and transportation. ${ }^{2-4}$.

Yet many of these efforts have omitted a vital contributor to health outcomes: caregiving (https://www.rolerevers alsblog.com/blog/2020/2/17/should-caregiving-be-consi dered-a-social-determinant-of-health). Understanding a person's caregiving context is critical for three reasons. First, the care patients receive in their homes-including unpaid informal care provided by family or friends, and care delivered by paid trained home care providers - has a significant influence on patient outcomes; ${ }^{5}$ for example, patients with more unmet caregiving needs have higher hospital readmission rates ${ }^{6}$ and are more likely to move to a nursing home or to die, than those whose care needs were met. ${ }^{7}$ Factors including whether a person lives with their caregiver, and the degree of caregiver burden, are associated with worse heart failure symptoms and quality of life, ${ }^{8}$ and are predictive of nursing home placement for older adults and persons with dementia. ${ }^{9,10}$ While the degree to which caregiver burden impacts institutionalization is unclear, interventions to improve caregiver well-being delay nursing home placement of persons with Alzheimer's disease. ${ }^{7,11,12}$ Second, informal caregivers themselves are at greater risk for poor health outcomes ${ }^{13,14}$ and are more likely to have impaired personal health behaviors, such as neglecting their own health. ${ }^{15}$ Up to a third of caregivers view their own health as fair or poor, ${ }^{16}$ an assessment that worsens with increasing duration of caregiving. ${ }^{17,18}$ The 2016 National Academies report, Families Caring for an Aging America (https://www. nap.edu/catalog/23606/families-caring-for-an-aging-ameri ca\#), documents the negative health impacts experienced 
by family caregivers, serving as a call to action. Informal caregivers often do not have access to resources to help with, or financial benefits for, caregiving activities. The estimated value of these unpaid activities was $\$ 470$ billion in 2019 (https://www.aarp.org/content/dam/aarp/ppi/2019/11/valui ng-the-invaluable-2019-update-charting-a-path-forward. doi.10.26419-2Fppi.00082.001.pdf). Even formal caregivers face risks as underpaid and low-benefit care providers. Third, it is essential to understand how care occurs in the home to achieve effective care coordination. By omitting caregiving from assessments of SDOH, health systems and clinicians miss an important opportunity to improve engagement in care, care delivery effectiveness, care plan adherence, and caregiver and care recipient health outcomes. Family caregivers disconnected from clinicians cannot reinforce treatment plans. Supporting family caregivers and integrating them into the healthcare team can offset the negative impacts of caregiving-related social determinants.

Just as COVID-19 underscored the impact of SDOH on outcomes, and the vulnerability of many groups within the USA, it also highlighted the susceptibility of formal and informal caregivers. ${ }^{16}$ Even prior to the pandemic, caregivers were more likely to report isolation, depression, and anxiety (https://www.caregiver.org/resource/caregiver-statisticshealth-technology-and-caregiving-resources/). The need to consider their own health risks, and those of their care recipients, increases caregivers' perceptions of social isolation, worsening their mental health. ${ }^{19}$ For example, surveys conducted early in the pandemic found that caregivers were 3.3 times as likely to have started or increased substance use as non-caregivers. ${ }^{20}$ Continued uncertainty about variants and safe activities may lead to prolonged negative impacts despite vaccine availability.

Caregiving intersects with other SDOH among underrepresented groups. Health inequities experienced by Black, Indigenous, and People of Color (BIPOC) extend to caregiving, as caregiving activities and access to resources differ depending on people's positions in society. Black persons over 65 are $30 \%$ more likely to be formal and informal caregivers than Whites, Latinos are more likely to provide home-based informal care to family members, and caregivers of color are more likely to experience worse health outcomes (https://www.apa.org/pi/about/publications/caregivers/faq/ cultural-diversity). ${ }^{21,22}$ Decreased access to care for BIPOC care recipients and caregivers, and differential resource access, both contribute to worse outcomes. While updated data on caregiving in the pandemic are limited, the most recent Caregiving in the US: 2020 report noted that compared with informal caregivers in other racial/ethnic groups, African American caregivers are more often unmarried, are employed outside of the home, live with their care recipient, and are more likely to report financial challenges (https:// www.caregiving.org/wp-content/uploads/2020/05/AARP1 316_CGProfile_AfricanAmerican_May7v8.pdf).
Based on the evidence regarding the impacts of caregiving on caregivers' and care recipients' health outcomes, and on our collective experience with research and clinical care, we recommend four strategies that health systems can undertake to better assess caregiving as important $\mathrm{SDOH}$, mitigate the health impact of formal and informal caregiving, and improve caregiver and care recipient outcomes.

First, health systems must support system-level changes to formally recognize and identify caregivers, incorporate them into care plans, and document this information in health records (https://www.nap.edu/resource/23606/CaregivingRiB.pdf). Accomplishing this requires talking about caregiving. Asking patients both for whom they care, and from whom they receive care, is critical to understanding their social circumstances. Reducing the invisibility of caregivers is necessary, but is complicated because many informal caregivers do not consider themselves "caregivers." Talking about caregiving activities is a first step for understanding each person's caregiving context. A second step is to assess the needs of families who provide informal caregiving. This can be accomplished by consistently collecting (and updating) information about caregiving activities in patient medical records as is done for other SDOH, including hours spent providing care, caregiving intensity, and strain.

Integrating caregivers into care plans improves outcomes. ${ }^{6,23,24}$ Caregivers are currently excluded in multiple ways. At a basic level, they are often physically excluded from discussions, even if unintentionally. Attending daytime outpatient appointments is difficult for caregivers who work, are in school, or have young children. In hospitals, inpatient teams are often absent during the evening and weekend times most convenient for caregivers. Care team huddles that loop in caregivers by phone could be a powerful approach for coordinating care. ${ }^{25}$ Harnessing the advantage of virtual visits and asynchronous communication may support caregivers' involvement in care discussions.

More data regarding effective ways to support and integrate caregivers are needed. However, limited evidence in targeted populations does demonstrate the importance of these supports (https://sites.nationalacademies.org/cs/ groups/dbassesite/documents/webpage/dbasse_198208.pdf). Care Interventions for People Living with Dementia and the Caregivers, an Agency for Healthcare Research and Quality comparative effectiveness review (https://effectivehealthcare. ahrq.gov/sites/default/files/pdf/cer-231-dementia-interventi ons-final_0.pdf), identified two promising multi-component interventions that improve caregiver and recipient outcomes: Collaborative Care $^{26}$ and Resources for Enhancing Alzheimer's Caregiver Health (REACH). ${ }^{27}$.

Second, we need a broad, coordinated scale-up of policies to support caregivers as part of our strategy to improve caregiver and recipient health outcomes. Coordinating care is often overwhelming for informal caregivers and could be improved by navigators, case managers, and advocates. ${ }^{28}$ 
Transportation or travel reimbursement, support groups, skills training, and respite care are examples of ways that health systems can directly support caregivers. Enhanced access to health information through effectively designed portals that endorse patient preferences for caregiver access while maintaining patient privacy and HIPAA requirements could better equip caregivers to understand care plans and communicate with clinicians. ${ }^{29}$ These efforts should be undertaken with a focus on digital equity so as to avoid exacerbating disparities in health care access. Health systems should partner with caregivers to understand and provide the supports that are most relevant for those they serve.

The Department of Veterans Affairs has undertaken several noteworthy initiatives that are examples of coordinated policies. The Caregiver Support Program (CSP) has established caregiver-specific points of contact at each VA medical center to connect caregivers with the health system. Caregiver coordinators help caregivers navigate community-based supports. Recently, COVID-19 vaccinations were expanded to include caregivers. ${ }^{30}$ Within CSP, the Program of Comprehensive Assistance for Family Caregivers (PCAFC) (https://www.caregiver.va.gov/support/New_ CSC_Page.asp) provides financial support for informal caregiving activities. The PCAFC's initial focus on post-9/11 veteran caregivers limited its reach, but it is among the most comprehensive caregiver support models yet implemented, and does appear to have increased non-institutional care. The VA Aid \& Attendance Benefit helps defray the cost of long-term care, but is limited to veterans receiving pensions (https://www.va.gov/pension/aid-attendance-housebound).

Third, we must incorporate the topics of "caregiving" and "inclusive care" 23 into health professions' educational curricula. So often, clinicians look into a patient room, see a large number of family members, and feel overwhelmed and unprepared to effectively communicate regarding uncertain situations. Instead, we have the opportunity to cultivate a mindset of seeing caregivers as extensions of the care team who will enable developing and enacting care plans. Initiatives like the Campaign for Inclusive Care promote this shift in thinking (https://campaignforinclusivecare.elizabethd olefoundation.org). ${ }^{31}$ Efforts to improve clinicians' skills in partnering with caregivers must be systematically applied, and married to system and policy changes noted above so that clinicians' attempts to engage caregivers are recognized as part of the work of usual care and operationally supported (https://www.nap.edu/catalog/23606/families-caring-for-anaging-america\#).

Fourth, health systems must develop robust partnerships with community programs and organizations that support caregivers. ${ }^{2}$ A public health approach to meeting caregiver needs could reduce unmet needs and improve caregiver and care recipient outcomes (https://www.rosalynncarter.org/wpcontent/uploads/2020/10/RCI_Recalibrating-for-Caregivers_ 2020.pdf). Coordination between public health agencies, area agencies on aging, non-profits, and the health care system is critical to support caregivers. Veteran Community partnerships, such as the Hidden Heroes City Campaign, are examples that empower collaborative action between VA and community partners to develop and expand personalized options for veterans and caregivers (https://www.va. gov/healthpartnerships/vcp.asp, https://hiddenheroes.org/ hidden-heroes-cities-and-counties/). The Veteran Directed Care Program (VDC), established as a VA/Administration for Community Living partnership, helps veterans eligible for nursing home care and their caregivers obtain needed services in their own homes (https://acl.gov/programs/veter an-directed-home-and-community-based-services/veter an-directed-home-community-based). Local public health agencies have also served as conveners of collaborations to support local communities. ${ }^{32}$ Other local health system and community partnerships provide examples of successful partnership models. ${ }^{33}$ Current inequities in available community resources will need to be identified and addressed.

Implementing these recommendations will be challenging, requiring coordinated action across multiple actors, from the local to the national level. Our four health system recommendations should be coupled with legislation that financially supports caregiving activities and expands community-based services. In Families Caring for an Aging America, the National Academies called for a National Family Caregiver Strategy encompassing specific initiatives with regard to caregiver identification, payment reform, training, and national data collection infrastructure (https://www.nap. edu/catalog/23606/families-caring-for-an-aging-america\#). These recommendations remain largely unrealized. Legislative action could support the provision of an expanded group of caregiver support services. The Biden administration's proposed American Families Plan would create a national comprehensive paid family and medical leave program (https://www.whitehouse.gov/briefing-room/statementsreleases/2021/04/28/fact-sheet-the-american-families-plan/). This program would support informal family caregivers for up to 12 weeks and would provide child care support that could benefit both informal family and formal caregivers. However, it does not address long-term caregiving activities often provided by family caregivers, and does not support those who are not employed outside the home. These are major omissions requiring further policy actions. Implementing solutions that reduce, rather than increase, health inequities for BIPOC caregivers is critical; expanding access to services for disadvantaged populations is necessary.

In summary, the need to mitigate the influence of SDOH on health outcomes and inequities has been recognized. Caregiving is an under-recognized, under-addressed contextual factor that significantly influences the health of recipients and caregivers. We suggest four health system actions to reduce negative outcomes associated with caregiving, and achieve better outcomes for individuals and more equitable 
care across communities. Committing to these efforts, and to ongoing evaluation of their implementation, will allow us to identify best practices at organizational, local, and national levels, and better understand how investments in integrated caregiving and care delivery are reflected in downstream costs, utilization, and improved patient and caregiver outcomes (https://timesupnow.org/care-economy-businesscouncil/).

\section{Acknowledgements}

Drs. Shepherd-Banigan and Van Houtven were supported by the Center of Innovation to Accelerate Discovery and Practice Transformation at the Durham VA Health Care System (Grant No. CIN 13-410) . Drs. Pugh (Mary Jo) and Van Houtven are supported by the U.S. Department of Veterans Affairs, Veterans Health Administration, Office of Research and Development, Research Career Scientist Program.

Funding This work is supported by the Health Services Research \& Development Service of the Department of Veterans Affairs (SDR 18-313). The views expressed are those of the authors and do not represent an official position of the Department of Veterans Affairs.

\section{Declarations}

Conflict of Interest The authors declare that they do not have a conflict of interest.

\section{REFERENCES}

1. [1] Hassan A, Scherer EA, Pikcilingis BA, Krull E, McNickles L, Marmon BA, Woods ER, Fleetler EW. Improving social determinants of health. Effectiveness of a web-based intervention. Am J Prev Med 2015. 49(6):822-31.

2. Murray GF, Rodriguez HP, Lewis VA. Upstream with a small paddle: How ACOs are working against the current to meet patients' social needs. Health Affairs 2020. 39(2). https://doi.org/10.1377/hlthaff. 2019.01266

3. Horwitz LI, Chang C, Arcilla HN, Knickman JR. Quantifying health systems' investments in social determinants of health, by sector, 2017-19. Health Affairs 2020. 39(2). https://doi.org/10.1377/hltha ff.2019.01246

4. [4] Jain SH, Chandrashekar P. Implementing a targeted approach to social determinants of health interventions. Am J Manag Care 2020. 26(12): 502-4

5. [5] Coe NB, Guo J, Konetzka RT, Van Houtven CH. What is the marginal benefit of payment-induced family care? Impact on Medicaid spending and health of care recipients. Health Econ. 2019;28(5):678-692

6. Rodakowski J, Rocco PB, Ortiz M, Folb B, Schulz R. Morton SC, Leahters SC, Hu L, James AE. Caregiver integration during discharge planning for older adults to reduce resource use: A metaanalysis. J Am Geriatr Soc 2017. 65(8):1748-55.

7. [7] Gaugler JE, Kane RL, Kane RA, et al. Unmet care needs and key outcomes in dementia. J Am Geriatr Soc 2005; 53(12): 2098-2105

8. [8] Bidwell JT, Lyons KS, Lee CS. Caregiver well-being and patient outcomes in heart failure: a meta-analysis. The Journal of cardiovascular nursing. $2017 \mathrm{Jul} ; 32(4): 372$.

9. [9] Wolff JL, Mulcahy J, Roth DL, Cenzer IS, Kasper JD, Huang J, Covinsky KE. Long-term nursing home entry: a prognostic model for older adults with a family or unpaid caregiver. Journal of the American Geriatrics Society. 2018 Oct;66(10):1887-94.

10. [10] Cepoiu-Martin, M., Tam-Tham, H., Patten, S., Maxwell, C. J., and Hogan, D. B. (2016) Predictors of long-term care placement in persons with dementia: a systematic review and meta-analysis. Int $\mathrm{J}$
Geriatr Psychiatry, 31: 1151- 1171. doi: https://doi.org/10.1002/ gps.4449.

11. [11] Mittelman MS, Haley WE, Clay OJ, Roth DL. Improving caregiver well-being delays nursing home placement of patients with Alzheimer disease. Neurology. 2006;67(9):1592-1599.

12. [12] Gaugler JE, Reese M, Mittelman MS. Effects of the NYU caregiver intervention-adult child on residential care placement. Gerontologist. 2013;53(6):985-997.

13. [13] Schulz R, Sherwood PR. Physical and mental health effects of family caregiving. Am J Nurs 2008. 108(9 suppl): 23-7.

14. National Research Council (US) Committee on the Role of Human Factors in Home Health Care. The Role of Human Factors in Home Health Care: Workshop Summary. Washington (DC): National Academies Press (US); 2010. 7, Informal Caregivers in the United States: Prevalence, Caregiver Characteristics, and Ability to Provide Care. Available from: https://www.ncbi.nlm.nih.gov/books/NBK210048/Accessed date 11-6-21

15. Burton LC, et al. Transitions in spousal caregiving. Gerontologist. 2003;43(2):230-41.

16. Friedman EM, tong PK, Rudin RS. The coronavirus pandemic highlights why family caregivers need to be integrated into the health care team and shows us how to make it happen. www.Rand.org/t/PEA10 79-1Accessed date 11-6-21

17. Bookwala J., Yee J.L., Schulz R. (2002) Caregiving and Detrimental Mental and Physical Health Outcomes. In: Williamson G.M., Shaffer D.R., Parmelee P.A. (eds) Physical Illness and Depression in Older Adults. The Plenum Series in Social/Clinical Psychology. Springer, Boston, MA. https://doi.org/10.1007/0-306-47178-7_6

18. [18] Del Pino Dasado R, Espinosa-Medina A, Lopez-Martinez C, Orgeta V. Sense of coherence, burden and mental health in caregiving: a systematic review and meta-analysis. J Affective Disorders 2019. 242:14-21.

19. Beach SR, Schulz R, Donovan H, Rosland AM. Family caregiving during the COVID-19 pandemic. The gerontologist 2021. https://doi.org/ 10.1093/geront/gnab049

20. Czeisler ME. Lane RI, Petrosky E, Wiley JF, Christensen A, Njai R, Weaver MD, Robbins R, Facer-Childs ER, Barger LK, Czeisler CA. Howard ME. Rajaratnam SMW. Mental health, substance use, and suicidal ideation during the COVID-19 pandemic - United States, June 24-30, 2020. Morb Mortal Wkly Rep 2020. 69(32):1049-57.

21. https://www.vox.com/2017/7/3/15872260/health-direct-care-jobs. Accessed April 16, 2020

22. [22] Spetz J, Stone RI, Chapman SA, Bryant N. Home and communitybased workforce for patients with serious illness requires support to meet growing needs. Health Affairs 2019. 6: 902-9.

23. Boucher NA, Shepherd-Banigan M, McKenna K, Delgado RE, Peacock $\mathrm{K}$, Van Houtven $\mathrm{CH}$. Inclusion of caregivers in Veterans' care: a critical literature review. Medical care research \& review 2020. https://doi. org/10.1177/1077558720944283

24. Shepherd-Banigan, M, Boucher, NA, McKenna, K, Delgado, RE, Whitaker, C, Christensen, L, Sperber, NR. Family caregiver and provider perspectives on inclusive care: alignment needs and expectations. Accepted for publication in Medical Care. June, 2021. https://europ epmc.org/article/med/34348392Accessed date 11-6-21

25. [25] Van Houtven CH, Hastings SN, Colon-Emeric C. A path to highquality team-based care for people with serious illness. Health Affairs 2019. 38(6):934-40.

26. [26] Callahan, CM, Malaz BA, Unverzagt FW et al. Effectiveness of collaborative care for folder adults with Alzheimer disease in primary care. JAMA 2006. 295(10):2148-57. Doi:https://doi.org/10.1001/ jama.295.18.2148

27. [27] Gitlin, L. N., Belle, S. H., Burgio, L. D., Czaja, S. J., Mahoney, D., Gallagher-Thompson, D., Burns, R., Hauck, W. W., Zhang, S., Schulz, R., \& Ory, M. G. (2003). Effect of multicomponent interventions on caregiver burden and depression: The REACH multisite initiative at 6-month follow-up. Psychology and Aging, 18(3), 361-374.

28. [28] Shepherd-Banigan M, Sperber N, McKenna K, Pagoda TK, Van Houtven $\mathrm{CH}$. Leveraging institutional support for family caregivers to meet the health and vocational of persons with disabilities. Nurs Outlook 2020. 68:184-93.

29. Latulipe C, Quandt SA, Melius KA, Bertoni A, Miller DP, Smith D, Arcury TA. Insights into older adult patient concerns around the caregiver proxy portal use: qualitative interview study. J Med Internet Res 2019. 20(11): e10524. 
30. Halley MC, Mangurian C. Caring for the caregivers - COVID-19 vaccination for essential members of the health care team. N Engl J Med 2021. https://doi.org/10.1056/NEJMpv2101339

31. Sperber N, Boucher NA, Delgado R, Shepherd-Banigan ME. McKenna K, Moore, M, Barrett R, Kabat M, Van Houtven CH. Including family caregivers in seriously ill Veterans' care: a mixed-methods study. Health Affairs 2019. 38: 957-63.

32. [32] Grenadier A, Holtgrave P, Aldridge C. Fostering agency through local public health. J Public Health Mgmt and Practice 2018. 24(4): 499-501.

33. Green SR, Singh V, O'Byrne W. Hope for New Jersey's city hospitals: the Camden Initiative. Perspect Health Inf Manag. 2010;7:1d. https://
www.ncbi.nlm.nih.gov/pmc/articles/PMC2889370/pdf/phim00070001d.pdf

Publisher's Note Springer Nature remains neutral with regard to jurisdictional claims in published maps and institutional affiliations. 